\title{
ВЛИЯНИЕ КАЧЕСТВА КАДАСТРОВОЙ ОЦЕНКИ НА ЭФФЕКТИВНОСТЬ УПРАВЛЕНИЯ МУНИЦИПАЛЬНЫМИ ОБРАЗОВАНИЯМИ
}

\section{Екатерина Николаевна Лосева}

Сибирский государственный университет геосистем и технологий, 630108, Россия, г. Новосибирск, ул. Плахотного, 10, аспирант; Новосибирский государственный университет экономики и управления, 630099, Россия, г. Новосибирск, ул. Каменская, 56, преподаватель кафедры экологической безопасности и управления природопользованием, тел. (383)243-95-14, e-mail: kaf-eco-lab@nsuem.ru

\section{Наталья Олеговна Митрофанова}

Сибирский государственный университет геосистем и технологий, 630108, Россия, г. Новосибирск, ул. Плахотного, 10, кандидат технических наук, доцент кафедры кадастра и территориального планирования, тел. (383)344-31-73, e-mail: kadastr-204@yandex.ru

В статье рассмотрено влияние качества кадастровой оценки и собираемости имущественных налогов на управление земельно-имущественным комплексом муниципального образования, актуальные проблемы, связанные с кадастровой оценкой объектов недвижимости, сформулированы предложения по разработке нового инструмента для расчета кадастровой стоимости объектов недвижимости.

Ключевые слова: управление земельно-имущественным комплексом, налог на имущество, кадастровая стоимость, государственная кадастровая оценка, земельные участки, объекты недвижимости, муниципальные образования, искусственные нейронные сети

\section{INFLUENCE OF QUALITY OF CADASTRAL ASSESSMENT ON EFFICIENCY OF MANAGEMENT OF MUNICIPAL EDUCATIONS}

\section{Ekaterina N. Loseva}

Siberian State University of Geosystems and Technologies, 10, Plakhotnogo St., Novosibirsk, 630108, Russia, Ph. D. Student; Novosibirsk State University of Economics and Management, 56, Kamenskaya St., Novosibirsk, 630099, Russia, Lecturer, Department of Environmental Safety and Management, phone: (383)243-95-14, e-mail: kaf-eco-lab@nsuem.ru

\section{Natalia O. Mitrofanova}

Siberian State University of Geosystems and Technologies, 10, Plakhotnogo St., Novosibirsk, 630108, Russia, Ph. D., Associate Professor, Department of Cadastre and Territorial Planning, phone: (383)344-31-73, e-mail: kadastr-204@yandex.ru

The article considers the impact of the quality of cadastral valuation and collection of property taxes on the management of the land and property complex of the municipality, topical problems associated with the cadastral valuation of real estate, formulated proposals for the development of a new tool for calculating the cadastral value of real estate.

Keywords: management of the land and property complex, property tax, cadastral value, state cadastral valuation, land plots, real estate, municipalities, artificial neural networks 


\section{Введение}

На эффективность управления земельно-имущественным комплексом муниципального образования (далее - ЗИК МО) влияет множество факторов: социальные, экономические, политические и др. Задача органов местного самоуправления грамотно распределять свои полномочия для достижения положительных результатов не только в определенный момент времени, но и работать на перспективу развития города [5].

В качестве объекта исследования выбран город Новосибирск. Новосибирск является тринадцатым по площади $\left(502 \mathrm{км}^{2}\right)$ и третьим по численности населения городом Российской Федерации, также крупнейшим городом Западно-Сибирского экономического района [4].

В современных условиях развития экономии бюджет муниципального образования является определяющим фактором для поддержания качества жизни населения на необходимом уровне. Одним из источников формирования бюджета муниципального образования является земельный налог, рассчитываемый исходя из кадастровой стоимости (далее - КС) земельных участков (далее - ЗУ).

Актуальность исследования обуславливается изменением законодательства в области кадастровой оценки и отсутствием современных инструментов ее расчета.

Цель исследования: исследовать влияние качества работ по кадастровой оценке на эффективность управления земельно-имущественным фондом муниципального образования и предложить пути совершенствования данного вида работ.

\section{Основная часть}

Одним из факторов эффективности управления земельно-имущественным комплексом муниципального образования выявлен процент собираемости налогов с учтенного имущества. Данный фактор зависит от двух показателей: количество зарегистрированного имущества и его кадастровая стоимость [7].

Кадастровая стоимость является одной из главных характеристик объектов недвижимости (далее ОН), которая определяется в результате государственной кадастровой оценки (далее - ГКО). Результаты ГКО используют для перспективной политики развития территорий, для эффективного управления территориями и справедливого расчета налогов [8]. Однако не всегда кадастровая стоимость рассчитывается правильно, из-за чего честно в комиссию по рассмотрению споров поступает большое количество заявлений. Результаты пересмотра кадастровой стоимости за 2017-2020 гг. представлены в таблице [2]. В результате видно, что при подаче заявления об оспаривании кадастровой стоимости большинство из них удовлетворяется, в результате чего кадастровая стоимость может быть снижена до $50 \%$. 
Статистика споров о результатах проведена кадастровой оценки

\begin{tabular}{|c|c|c|c|c|}
\hline Год & $\begin{array}{c}\text { Количество по- } \\
\text { данных исков }\end{array}$ & $\begin{array}{c}\text { Удовлет- } \\
\text { ворено } \\
\text { исков }\end{array}$ & $\begin{array}{c}\text { Снижение кадастровой стоимости } \\
\text { в результате удовлетворения иска, } \\
\text { млрд. руб. }\end{array}$ & $\begin{array}{c}\text { Изменение ка- } \\
\text { дастровой стои- } \\
\text { мости ОН, \% }\end{array}$ \\
\hline 2017 & 97 & 70 & 5,4 & $-49,3$ \\
\hline 2018 & $69(723 У)$ & 56 & 4,8 & $-49,0$ \\
\hline 2019 & $105(943 У)$ & - & 9,6 & $-39,8$ \\
\hline $\begin{array}{c}2020(9 \text { ме- } \\
\text { сяцев) }\end{array}$ & - & - & 6,1 & $-46,2$ \\
\hline
\end{tabular}

В качестве оснований для подачи заявлений о пересмотре КС ОН стоит обозначить следующие:

- в связи с выявлением недостоверных сведений об объекте оценки ошибка возникает в результате неправильного определения группы видов разрешенного использования ЗУ и в связи с исправлением технической и (или) кадастровой ошибки;

- несоответствие отчетов об определении стоимости объектов недвижимости законодательству об оценочной деятельности и (или) федеральным стандартам оценки;

- установления рыночной стоимости объектов недвижимости на дату определения их кадастровой стоимости;

- единичные методологические ошибки.

Так как кадастровая оценка проводится массово, существуют вероятность допущения подобных и других ошибок. Также массовая оценка не учитывает индивидуальных особенностей объектов недвижимости.

В целях совершенствования системы кадастровой оценки ОН 03.07.2016 года был принят федеральный закон «О государственной кадастровой оценке» № Ф3-237 [10]. В соответствии с данным законом ГКО проводится на основании принципов единства методологии определения кадастровой стоимости, для этого все необходимые сведения об ОН должны быть актуализированы, каждый этап ГКО должен осуществляться с экономической обоснованностью, а все результаты ГКО должны быть проверены. Данный закон также предусматривает создание государственных бюджетных учреждений, которые наделены полномочиями, связанными с определением КС ОН, а также рассмотрением заявлений об оспаривании кадастровой стоимости.

В настоящее время на территории Новосибирской области создано государственное бюджетное учреждение «Центр кадастровой оценки и бюро технической инвентаризации» (ГБУ НСО «ЦКО и БТИ») [3]. Данное бюджетное учреждение предоставляет услугу по определению КС ОН. Для этого собирается большой массив данных об ОН, затем выбирают способ оценки путем использования статистических и математических методов, обосновывается выбор метода оценки, проводится расчет кадастровой стоимости и в завершении проводится 
проверка проведенных работ по оценке. Все перечисленные виды работ сопровождаются обработкой большого массива данных [9].

В целях совершенствования системы и возможного перехода от массовой оценки к индивидуальной, при которой будут учитываться все индивидуальные особенности объектов недвижимости, предлагается использовать новые технологии, а именно искусственные нейронные сети (далее - ИНС).

На данный момент для целей расчета рыночной стоимости объектов капитального строительства проводятся исследования по применению нейронных сетей. Например, в своих исследованиях С.С Питулин разрабатывает сеть, которая прогнозирует цены на недвижимость в Смоленской области [1].

ИНС - это математическая модель обработки информации, а также ее программное воплощение, которое построено по принципу работы нервных клеток живого организма. Основная цель работы такой сети - обучиться «самостоятельно» принимать решения в сложных ситуациях и решение задач с учетом изменяющихся факторов так, как это делает человек. Схема работы ИНС представлена на рисунке.

Рассмотрим принцип работы искусственной нейронной сети. Для обучения нейронной сети необходимо собрать массив данных, то есть информацию о факторах, которые влияют на каждый объект недвижимости, причем, эти факторы должны быть в избытке, для того, чтобы нейронная сеть могла обучиться. Далее предполагается задать вес каждому фактору из расчета, который делает специалист, затем, нейронная сеть при первом расчете использует разработанные удельные показатели и приходит к объективно рассчитанной стоимости объекта. Затем нейронная сеть распределяет ошибку в обратном направлении и таким образом сама назначает веса каждому фактору. После прохождения нескольких тысяч случаев нейронная сеть снижает ошибку расчета, таким образом, достигая необходимой точности [6].

После того как нейронная сеть обучена, она может работать самостоятельно, при этом, самостоятельно назначая удельные веса факторам. ИНС рассчитывает значение подобно тому, как при массовой оценке рассчитывают удельный показатель кадастровой стоимости (УПКС), который умножается на площадь объекта и в результате получается кадастровая стоимость, которая рассчитана с учетом индивидуальных особенностей объекта.

Согласно Ф3-269 от 31.07.2020 «в 2022 году во всех субъектах Российской Федерации должна быть проведена государственная кадастровая оценка земельных участков без учета ограничений по периодичности проведения государственной кадастровой оценки», а это значит, что объем работ увеличится в несколько раз, что может привести к увеличению ошибок при определении КС [11]. Поэтому разработка подобного рода системы способно снять нагрузку с бюджетных учреждений и повысить точность определения КС, что в дальнейшем снизит процент оспаривания КС. 


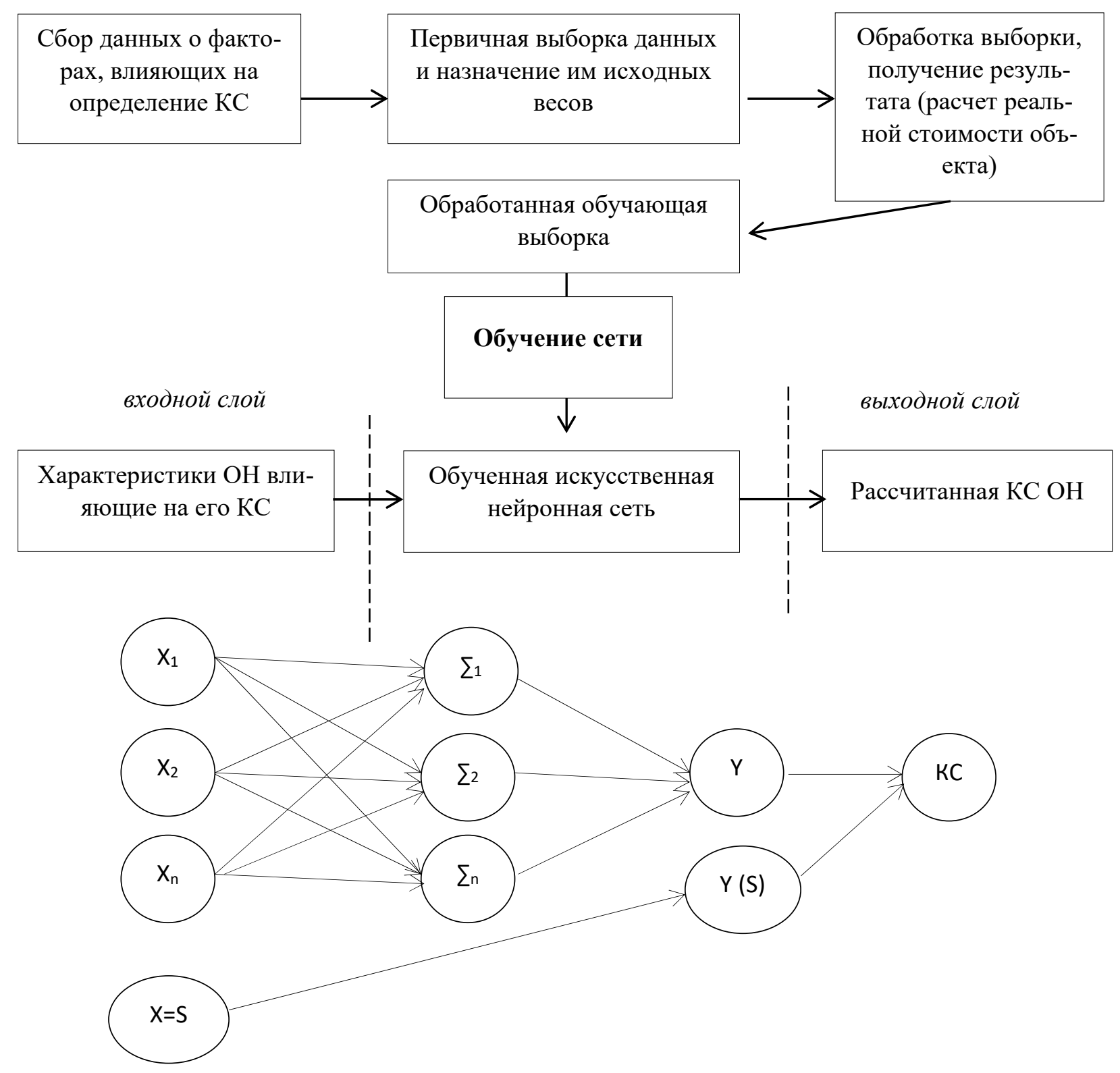

Рис. 1. Схема работы искусственной нейронной сети

Разработка ИНС для целей расчета кадастровой стоимости предполагает достижение следующих результатов:

- исключение субъективных факторов при определении вида разрешенного использования и отнесения ОН к определенной группе;

- сокращение времени оценки, что в свою очередь увеличит количество оцениваемых объектов, а значит, сроки будут советовать федеральным законам $[10,11]$;

- расчет земельного налога будет эффективнее;

- использование только тех факторов, которые влияют на стоимость конкретного объекта, исключение факторов которые могли бы завысить КС, но не 
влияют на данный объект. Это может быть реализовано потому, что каждый объект будет оцениваться индивидуально, а не обобщаться с другими ОН в группы;

- исключатся необходимость обоснования метода оценки и оценки точности выбранного метода, а значит сокращение времени оценки в целом.

\section{Вывод}

На сегодняшний день представителями научного и профессионального сообщества проведены научные исследования только в отношении расчета или прогноза рыночной стоимости объектов капитального строительства, с применением искусственных нейронных сетей. В отношении расчета кадастровой стоимости ЗУ в границах населенных пунктов данный инструмент не применяется.

Не смотря на попытки совершенствования методики проведения ГКО ОН остается большое количество споров из-за того, что КС завышается, а занижение КС ведет к потере налогов, поступающих в бюджет МО.

В целях сохранения актуальной кадастровой стоимости при нестабильной экономике страны следует постоянно актуализировать данные об ОН и их кадастровую стоимость, то есть проводить оценку чаще.

Из-за возрастающей нагрузки (множество объектов недвижимости и информации о них, пересчет КС при ее оспаривании, сокращение периода переоценки) следует применять современные механизмы определения КС.

Рассмотренные вопросы позволяют сделать вывод о прямой взаимосвязи количества учтенных объектов недвижимости и объективности результатов кадастровой оценки на экономическое состояние муниципального образования.

Дальнейшее исследование будет посвящено разработке инструмента для более качественного расчета КС ЗУ и исключения факторов, влияющих на допущение ошибки при расчётах - создание искусственной нейронной сети.

\section{БИБЛИОГРАФИЧЕСКИЙ СПИСОК}

1. Питулин С.С. Применение нейронных сетей для прогноза динамики цен на недвижимость в Смоленской области - Журнал NOVAINFO.RU - Москва. 2019. C.4-6 [Электронный pecypc] Режим доступа: https://www.elibrary.ru/item.asp?id=41540835 (дата обращения: 10.11.2020).

2. Сайт Росреестра [Электронный ресурс] Режим доступа: https://rosreestr.gov.ru/site/open-service/statistika-i-analitika/gosudarstvennaya-kadastrovayaotsenka-obektov-nedvizhimosti/ (дата обращения: 16.11.2020).

3. Сайт Центра кадастровой оценки и бюро технической инвентаризации» (ГБУ НСО «ЦКО и БТИ») [Электронный ресурс] Режим доступа: http://www.noti.ru/ (дата обращения: 13.11.2020).

4. Сайт мэрии города Новосибирска [Электронный ресурс] Режим доступа: https://novosibirsk.ru/about/districts/ (дата обращения: 07.11.2020).

5. Лосева. Е.Н. Анализ основных функций органов местного самоуправления в области управления земельно-имущественным комплексом // Сборник материалов национальной научно-практической конференции «Регулирование земельно-имущественных отношений в России: правовое и геопространственное обеспечение, оценка недвижимости, экология, технологические решения» в двух частях, Часть 1 - Новосибирск. СГУГиТ. - д 2020. С. $22-28$ [Электронный ресурс] Режим доступа: https://www.elibrary.ru/item.asp?id=44099945 - (дата обращения 13.11.2020). 
6. Арефьева Е.Н. Использование нейронных сетей для оценки рыночной стоимости недвижимости // Е.А. Арефьева, Д.С. Костяев - Технические науки. 2017. №10. [Электронный pecypc] Режим доступа: https://cyberleninka.ru/article/n/ispolzovanie-neyronnyh-setey-dlyaotsenki-rynochnoy-stoimosti-nedvizhimosti (дата обращения: 13.11.2020).

7. Положение «О земельном налоге на территории города Новосибирска» Приложение к решению городского Совета от 25.10.2005 № 105 (В редакции, введенной решением Совета депутатов г. Новосибирска от 23.10.2019 № 860) [Электронный ресурс] Режим доступа: http://docs.cntd.ru/document/5420097 (дата обращения: 07.11.2020).

8. Жданова Р.В. Применение результатов государственной кадастровой оценки при управлении земельными ресурсами / Р.В. Жданова, А.В. Матвеева - МСХ. 2019. №3. [Электронный ресурс] Режим доступа: https://cyberleninka.ru/article/n/primenenie-rezultatovgosudarstvennoy-kadastrovoy-otsenki-pri-upravlenii-zemelnymi-resursami (дата обращения: 13.11.2020).

9. Методические указания о государственной кадастровой оценке утвержденные приказом Минэкономразвития России от 12.05.2017 года № 226 (с изменениями на 9 сентября 2019 года) [Электронный ресурс] Режим доступа: http://docs.cntd.ru/document/456065252.

10. Федеральный закон «О государственной кадастровой оценке» от 03.07.2016 № 237Ф3 [Электронный ресурс] Режим доступа: http://www.consultant.ru/document /cons_doc_LAW_200504/(дата обращения: 10.11.2020).

11. Федеральный закон от 31.07.2020 № 269-Ф3 «О внесении изменений в отдельные законодательные акты Российской Федерации» [Электронный ресурс] Режим доступа: http://www.consultant.ru/document/cons_doc_LAW_358790/(дата обращения: 09.11.2020).

(C) Е. Н. Лосева, Н. О. Митрофанова, 2021 